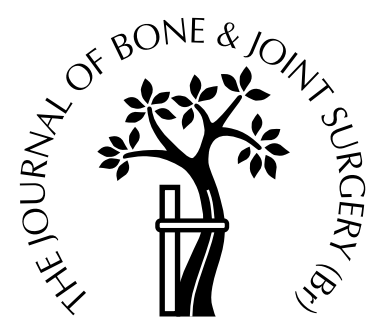

\title{
Editorials
}

\section{A CHANGE OF EDITOR}

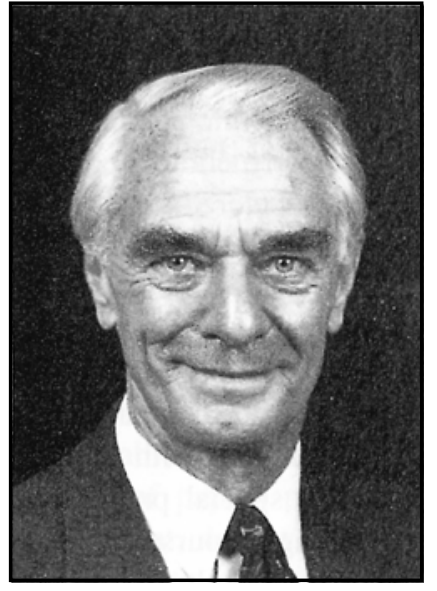

Philip Fulford retired as Editor of the British volume of the Journal of Bone and Joint Surgery at the end of April 1998. He had held the post of Editor since November 1994, but his close working relationship with the Journal goes back nearly 20 years. When he first joined the Editorial Board in 1980 he was still practising as an orthopaedic surgeon in the Royal Navy. He had a distinguished Service career, becoming Professor of Naval Surgery, as well as being appointed CVO and OBE for his services to the Queen and to naval surgery. After his retirement from the Navy, he worked for a period as a civilian consultant in orthopaedic surgery in the Wessex Region, but was soon lured back to the Journal, which he joined as Deputy Editor in 1986. He occupied that post for a period of eight years and became the acknowledged expert within the organisation on all aspects of editing, production, and publication before succeeding John Goodfellow as Editor. His continued enthusiasm and devotion to the Journal have strengthened its impact on orthopaedic surgery worldwide, and has led to the expansion of its publishing activities. This has been most evident in the growth of the Proceedings, the introduction of a new Research Section, and the publishing support for EFORT. His experience and wise counsel will be missed, although not entirely lost by the Journal, since he has agreed to continue as Editor Emeritus.
D.H.

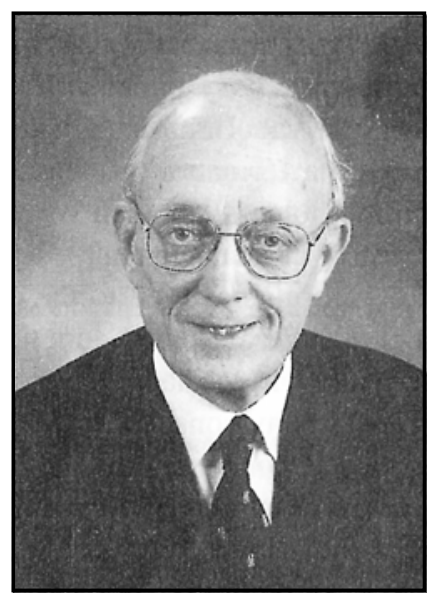

Frank Horan became the sixth Editor of the British volume of the Journal of Bone and Joint Surgery in May 1998. He brings to the post a considerable knowledge of the Journal's activities, having served as a member of the Editorial Board from 1982-85, as Associate Editor from 1994-96 and then as Deputy Editor. He has the additional advantage of a broad experience in medical publishing, having been Associate Editor and later Chairman of the Editorial Board of International Orthopaedics, and Editor of the Newsletter of the British Orthopaedic Association. He has recently retired from the National Health Service, after a distinguished career as a consultant orthopaedic surgeon and later Medical Director of the Princess Royal Hospital, Haywards Heath. His particular clinical interests were in bone dysplasias and he has written extensively on this subject. His keen personal interest in cricket is also reflected in his involvement in sports medicine and his role as a Medical Adviser to the English Cricket Board and to the MCC at Lord's . Through his work with SICOT he has developed extensive international links which will be invaluable in the continued objective of the British volume to serve a broader, worldwide authorship and readership. We congratulate him on his appointment and wish him every success in his new post.

D.H. 